\title{
Finite Element Simulation Analysis for Concrete Arch Dam of Menkanshao Reservoir
}

\author{
Liu Keding \\ Hunan Urban Construction College \\ Xiangtan, China \\ 297298755@qq.com
}

\begin{abstract}
The loads on the arch dam and the materials physical properties of the dam and the bedrock are uncertain, and can be described with random variable. Due to the huge volume, the complex structure of the dam and excessive random variable, the static analysis of the dam is difficult. The dam is a higher order statically indeterminate structure, and the variation of the temperature obviously affects the stress and displacement of the structure, therefore, it is very important to consider the randomness of the temperature change load in the static analysis of arch dam. Concrete arch dam is a common hydraulic structures, using finite element method threshold whistle singles concrete arch dam reservoir finite element analysis to calculate the arch in normal operation phase maximum stress and deformation. The results were analyzed and explained, singles concrete arch dam design and construction to provide a certain reference value.
\end{abstract}

Keywords- Menkanshao reservoir; Single arch; Finite element method; Circumferential stress; Static analysis.

\section{ENGINEERING SITUATION}

Menkanshao reservoir is located in the Yalu Pushihe tributaries of Kuandian County Liaoning Province, control drainage area above the dam site $198 \mathrm{~km}^{2}$,total reservoir capacity of 1.26 million $\mathrm{m}^{3}$.Project by the dam, diversion tunnel, pressure pipes, factories and other buildings. The dam is a concrete single arch fixed circle fixed outer radius, the maximum height of $20.2 \mathrm{~m}$,dam bottom thickness $1.1 \mathrm{~m}$,thicker than 0.08.Dam normal water level $14.6 \mathrm{~m}$,design water level $17.2 \mathrm{~m}$,check flood level $19 \mathrm{~m}[1]$.

\section{ARCH CALCULATION MODEL}

Menkanshao trapezoidal Valley Reservoir Dam is located in the valley sides pier gravity dam foundation for hard red meat, fine-grained granite and the two sides is weak weathered granite. Granite riverbed is breeze[2].Rock elastic modulus $E_{1}=22 \mathrm{GPa}$, poisson's ratio $\mu_{1}=0.28$, concrete arch dam reservoir uses the concrete strength class $\mathrm{C} 25$, elastic modulus $E_{2}=28 \mathrm{GPa}$, poisson's rati $\mu_{2}=0.167 \quad$ [3-4],Bulk density $\gamma_{1}=24 \mathrm{kN} / \mathrm{m}^{3}$.

Concrete arch dam and bedrock structure model uses 8 -node isoparametric block element.The element is applied to three-dimensional model entity structure,has plasticity,creep,swelling,stress stiffening,large deformation and large strain properties. The element has eight nodes and each node has three translational degrees of freedom[5-7].

Considering the arch structure during operation of the mechanical characteristics[8-9],the main consideration of the following three kinds of calculation condition is that case1(normal water level and weight),case2(design water level, tail water level and weight),case3(check flood level, tail water level and weight).

\section{THE RESULTS ANALYSIS}

\section{A Analysis Path}

Concrete arch dam reservoir on the Menkanshao structural finite element analysis, the arch dam upstream face analysis to define a path to calculate the critical points along the crest every $3.37 \mathrm{~m}$ to take an arch dam at the end, for a total of seven critical computing points.

\section{B Stress Analysis}

Case 1:Under the arch of the largest ring tensile stress is $0.83 \mathrm{MPa}$,which appears in the left bank of the rock arch dam abutment junction. Maximum circumferential stress is $-2.50 \mathrm{MPa}$,appeared in the middle arch arch crown. Maximum vertical tensile stress is $3.71 \mathrm{MPa}$,appeared in the bottom arch dam at the junction with the bedrock, the maximum vertical stress for $-4.43 \mathrm{MPa}$,appeared in the middle arch arch crown.

Case 2:Under the arch of the largest ring tensile stress is $1.12 \mathrm{MPa}$,the maximum circumferential stress for $-3.48 \mathrm{MPa}$. The maximum vertical tensile stress is $5.21 \mathrm{MPa}$, the maximum vertical stress for $-5.75 \mathrm{MPa}$.Each direction of maximum stress values appear location and case 1 is basically the same.

Case 3:Under the arch of the largest ring tensile stress is $1.32 \mathrm{MPa}$, the maximum circumferential stress for $-4.17 \mathrm{MPa}$. The maximum vertical tensile stress is $6.26 \mathrm{MPa}$, the maximum vertical stress for $-6.66 \mathrm{MPa}$. Each direction of maximum stress values appear location and case 1 is basically the same.

Arch structure analysis of path computation in the conditions on the key points of circumferential stress, vertical stress values can be seen in Table 1 . 
TABLE I. EACH ROUTE CALCULATION CONDITIONS ARCH STRUCTURE ANALYSIS ON THE KEY POINTS OF STRESS

\begin{tabular}{|c|c|c|c|c|c|c|c|c|}
\hline \multicolumn{2}{|c|}{ Location } & (1) & (2) & (3) & (4) & (5) & (6) & (7) \\
\hline \multirow{2}{*}{ Case 1} & $\begin{array}{c}\text { Circumferentia } \\
\text { I stress }\end{array}$ & 0.674 & -1.004 & -2.081 & -1.797 & -0.967 & -0.414 & 0.147 \\
\hline & Vertical stress & 3.646 & -0.806 & -2.211 & -1.276 & -0.258 & -0.003 & -0.002 \\
\hline \multirow{2}{*}{ Case 2} & $\begin{array}{c}\text { Circumferentia } \\
\text { I stress }\end{array}$ & 0.941 & -1.282 & -2.926 & -2.825 & -1.793 & -0.924 & -0.007 \\
\hline & Vertical stress & 5.140 & -0.599 & -2.734 & -1.920 & -0.695 & -0.126 & -0.007 \\
\hline \multirow{2}{*}{ Case 3} & $\begin{array}{c}\text { Circumferentia } \\
\text { I stress }\end{array}$ & 1.132 & -1.464 & -3.505 & -3.575 & -2.501 & -1.492 & -0.373 \\
\hline & Vertical stress & 6.194 & -0.416 & -3.025 & -2.283 & -0.995 & -0.278 & -0.021 \\
\hline
\end{tabular}

As can be seen from Table 1, under pressure and its own weight, arch dam at the end of the hoop tensile stress occurs, crest ring stress value to small, circumferential stress in other locations are stress. Under pressure and its own weight, arch dam at the end, there was greater vertical tensile stress, vertical stress in other locations are stress. And with the increase in water pressure, arch ring increases stress and vertical stress.

In case 2 under the arch circumferential stress, vertical stress,the first principal stress and the third principal stress contour map see Fig .1 to Fig .4.We can be seen from Fig .1 to Fig .4 , the entire central arch stress distribution is more uniform,but in the arch and arch dam abutment at the end of the junction of the bedrock values of greater stress. This is mainly caused by the stress concentration of the herein. These larger tensile stress value may be reduced by the equivalent stress finite element method[10].

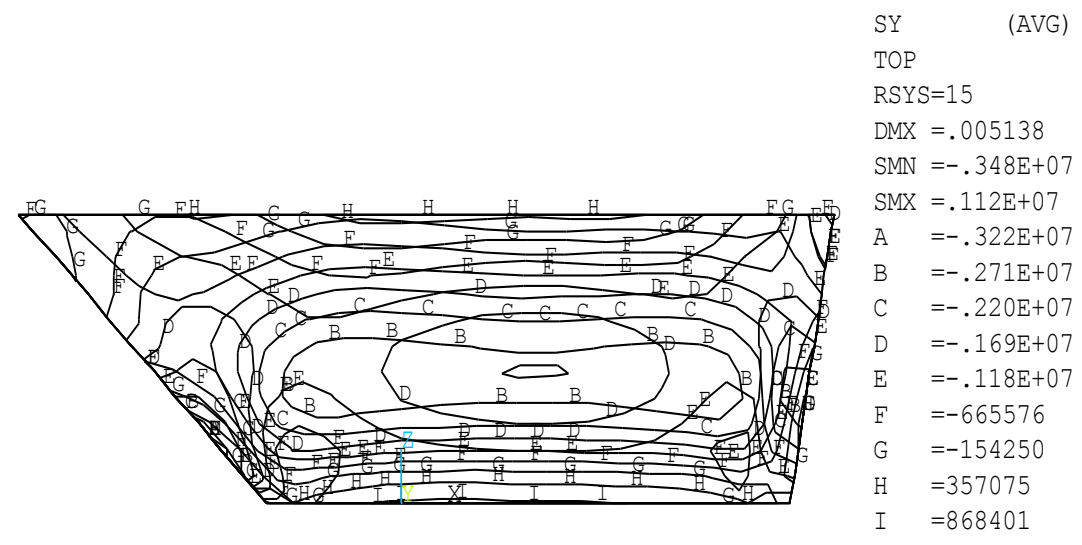

Figure 1. Arch's contour map of circumferential stress under case $2(\mathrm{~Pa})$

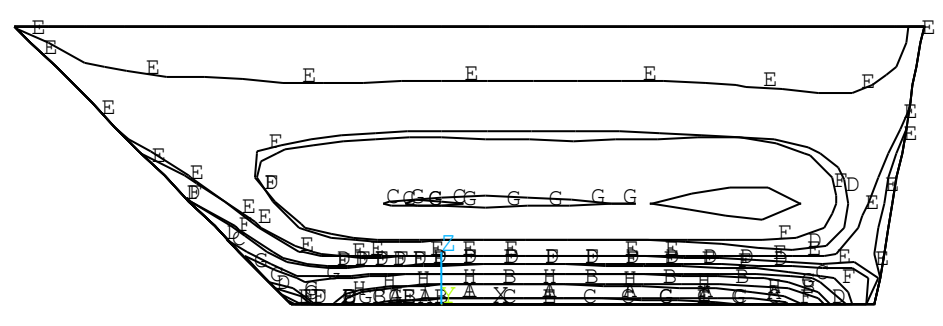

Figure 2. Arch's contour map of vertical stress under case 2( $\mathrm{Pa})$ 


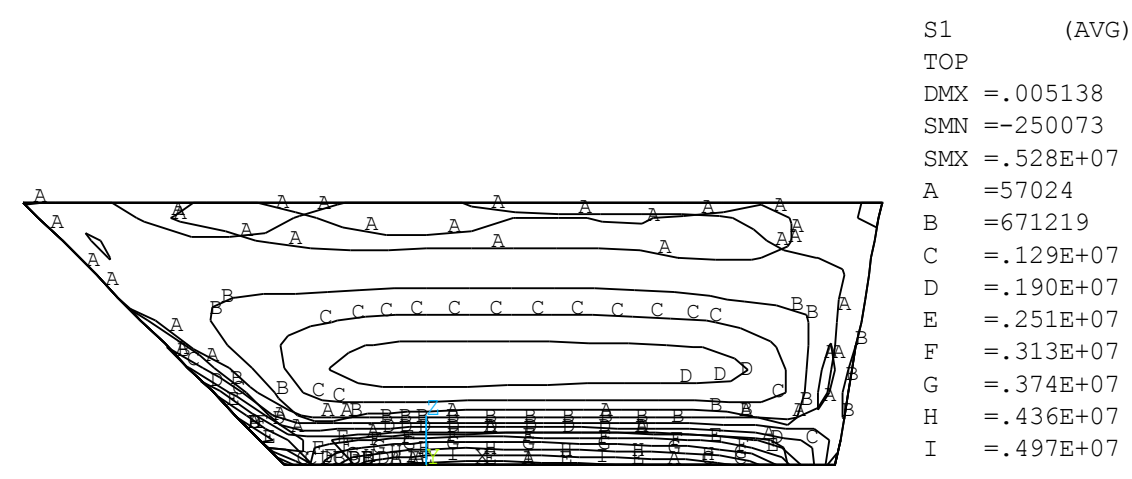

Figure 3. Arch's contour map of first principal stress under case $2 \quad(\mathrm{~Pa})$

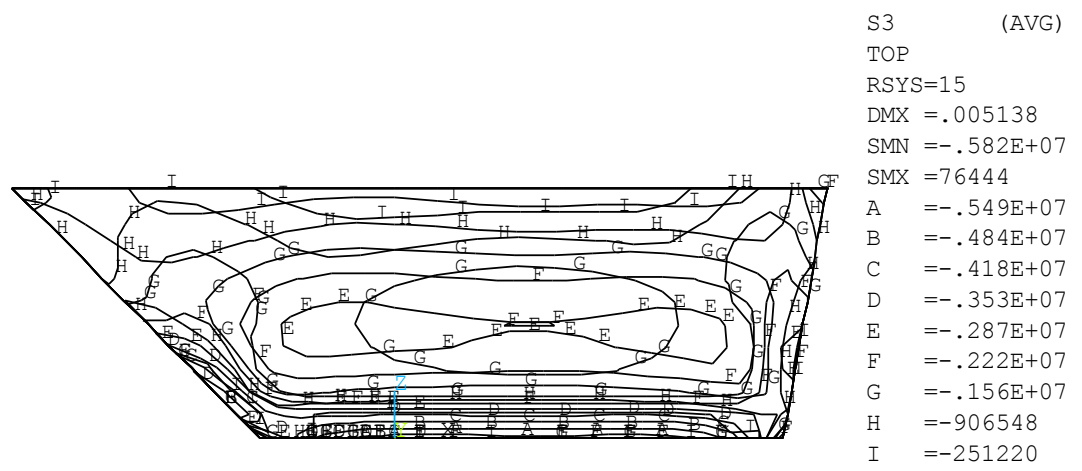

Figure 4. Arch's contour map of third principal stress under case 2( $\mathrm{Pa})$

\section{Deformation Analysis}

Case 1:The maximum radial displacement under the arch of $3.40 \mathrm{~mm}$,appeared in the middle arch arch crown.The maximum vertical displacement arch of $1.55 \mathrm{~mm}$, appeared in the arch at the top of the left abutment.

Case 2:The maximum radial displacement under the arch of $5.02 \mathrm{~mm}$,appeared similar to case 1.The maximum vertical displacement arch of $1.57 \mathrm{~mm}$, appeared similar to case 1 .
Case 3:The maximum radial displacement under the arch of $6.25 \mathrm{~mm}$,appeared similar to case 1.The maximum vertical displacement arch of $1.66 \mathrm{~mm}$, appeared similar to case 1 .

Through concrete arch structure deformation of Menkanshao reservoir analysis, the calculated structural analysis of various conditions arch radial displacement path computation on key points, the displacement calculation results are shown in Table 2.

TABLE II. STRUCTURAL ANALYSIS OF EACH CASES IN THE ROUTE CALCULATION ABOUT AQUEDUCT IN THE RADIAL DISPLACEMENT VALUE OF THE KEY

\begin{tabular}{|c|c|c|c|c|c|c|c|}
\hline Location & (1) & (2) & (3) & (4) & (5) & (6) & (7) \\
\hline Case 1 & -0.024 & -1.676 & -3.158 & -3.139 & -2.264 & -1.570 & -0.822 \\
\hline Case 2 & -0.034 & -2.285 & -4.538 & -4.847 & -3.778 & -2.713 & -1.479 \\
\hline Case 3 & -0.040 & -2.711 & -5.525 & -6.144 & -5.080 & -3.865 & -2.381 \\
\hline
\end{tabular}

As can be seen from Table 2, in the water pressure and its own weight, the dam at the end of the radial position is very small, which is mainly due to the dam at the end constraints of the bedrock, the rigidity is large. The radial displacement is small. From the bottom to the top of the dam, arch of the radial displacement increased first and then decreased, the radial displacement of the largest central arch, which is mainly generated displacement distribution of water pressure.

Fig.5 to Fig.6 in case 2 under arch radial displacement and vertical displacement contour were shown. 


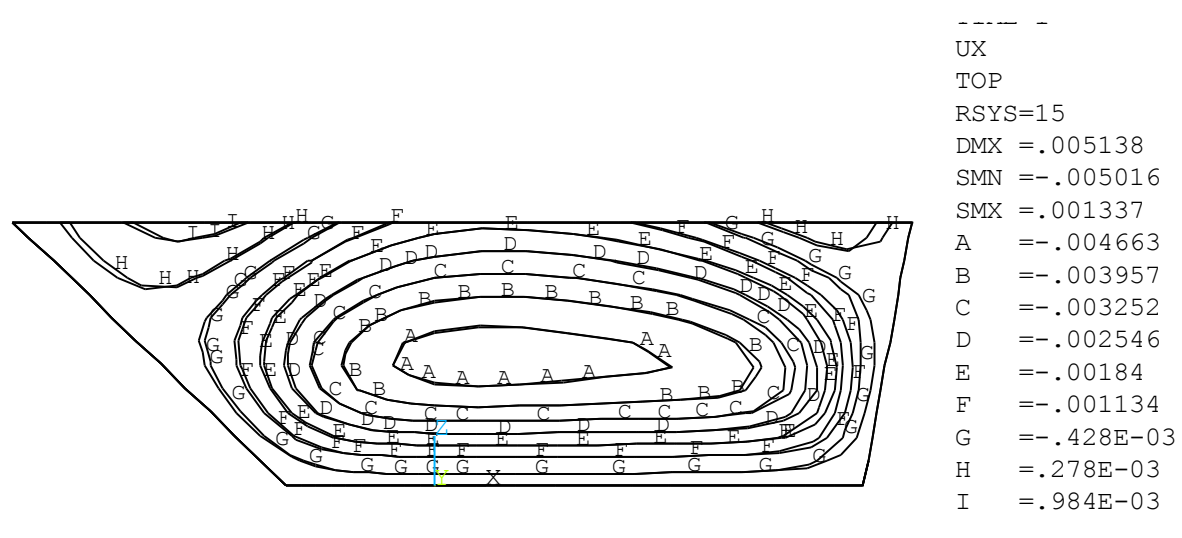

Figure 5. Arch's contour map of radial displacement under case 2(m)

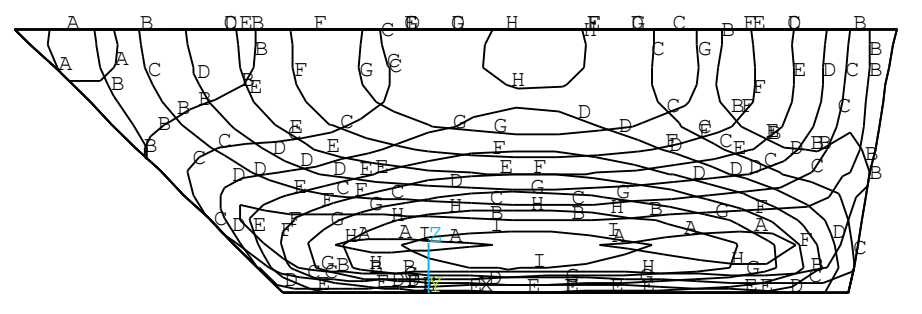

$$
\begin{aligned}
& \text { UZ } \\
& \text { TOP } \\
& \text { RSYS }=15 \\
& \text { DMX }=.005138 \\
& \text { SMN }=-.001572 \\
& \text { SMX }=-.617 \mathrm{E}-03 \\
& \text { A }=-.001519 \\
& \text { B }=-.001413 \\
& \text { C }=-.001306 \\
& \text { D }=-.0012 \\
& \text { E }=-.001094 \\
& \text { F }=-.988 \mathrm{E}-03 \\
& \text { G }=-.882 \mathrm{E}-03 \\
& \text { H }=-.776 \mathrm{E}-03 \\
& \text { I }=-.670 \mathrm{E}-03
\end{aligned}
$$

Figure 6. Arch's contour map of vertical displacement under case 2(m)

As can be seen from Fig .5 to Fig .6,the maximum radial displacement of the arch mainly appeared in the central arch. The maximum vertical displacement occurred mainly in the top of the abutment. But Arch radial displacement larger than the vertical displacement, which is mainly caused by water pressure, and water pressure has little effect on the vertical displacement of the arch.

\section{CONCLUDING ReMARKS}

The results show that the Menkanshao reservoir during normal operation phase the overall stress value is not big than be able to meet the strength requirements. Radial displacement of the main hydraulic pressure generated by also small so that it can be meet the requirements.

\section{REFERENCES}

[1] Bans Sevim,Ahmet Can Altunisik,Alemdar Bayraktar et al. Estimation of Elasticity Modulus of a Prototype Arch Dam Using Experiments" Methods [J]. Journal of Materials in Civil Engineering,2012,24(4):321-329.

[2] Bans Sevim,Ahmet Can Altunisik,Alemdar Bayraktar et al. Earthquake Behavior of Berke Arch Dam Using Ambient Vibration Test Results [J]. Journal of Performance of Constructed Facilities,2012,26(6):780-792.
[3] SL191-2008. Design Code for Hydraulic Concrete Structure[S] China Water Conservancy and Hydropower Press, 2008.

[4] Wen-ping Fei, Lin Zhang, Ru Zhang et al. Experimental study on a geo-mechanical model of a high arch dam [J]. International Journal of Rock Mechanics and Mining Sciences, 2010, 47(2):299-306.

[5] Bofang Zhu. Finite Element Method Principle and Application [M]. China Water Conservancy and Hydropower Press, 1998.

[6] Li Shouyi,Ding Lujun,Zhao Lijuan et al. Optimization design of arch dam shape with modified complex method [J]. Advances in Engineering Software,2009,40(9):804-808.

[7] Xucheng Wang. Finite Element Method [M]. Tsinghua University Press, 2003.

[8] Bans Sevim,Alemdar Bayraktar,Ahmet Can Altunisik et al. Investigation of water length effects on the modal behavior of a prototype arch dam using operational and analytical modal analyses $[\mathrm{J}]$. Structural engineering and mechanics,2011,37(6):593-615.

[9] Baris Sevim,Alemdar Bayraktar,Ahmet Can Altunisik et al Modal Parameter Identification of a Prototype Arch Dam Using Enhanced Frequency Domain Decomposition and Stochastic Subspace Identification Techniques[J] . Journal of Testing and Evaluation,2010,38(5):588-597.

[10] Bofang Zhu, Jizhang Gao, Zuyu Chen, Yisheng Li. Arch Dam Design and Research $[\mathrm{M}]$. China Water Conservancy and Hydropower Press, 2002. 